\title{
Tailoring Properties of Polylactic Acid/Rubber/Kenaf Biocomposites: Effects of Type of Rubber and Kenaf Loading
}

\author{
Nur Fazreen Alias, Hanafi Ismail,* and Ku Marsilla Ku Ishak
}

\begin{abstract}
Polylactic acid (PLA) biocomposites were prepared by melt blending in an internal mixer with various types of rubber. The rubber was $90 / 10$ $\mathrm{wt} \%$ and was mixed before the addition of kenaf fiber ( 0 to $20 \mathrm{phr}$ ). Natural rubber (NR), nitrile butadiene rubber (NBR), and styrene butadiene rubber (SBR) were used. The effects of different types of rubber and kenaf loading were investigated based on processing torque, water absorption, mechanical properties, and fractured surface morphology. A similar trend in processing torque was observed throughout the composition of biocomposites. The stabilization torque was highest for the biocomposite with NR, followed by SBR and NBR. Water absorption increased as the kenaf loading increased. The polarity of NBR and SBR contributed to higher water absorption in the biocomposites compared to the NR. The strain-induced crystallization phenomenon and higher green strength of NR contributed to the highest tensile strength, elongation at break, and impact strength of the biocomposite compared to the NBR and SBR toughened PLA/kenaf biocomposite. More plastic deformation and less fiber pullout were observed in the fractured surface morphology. However, by increasing the kenaf loading, the mechanical properties decreased for all biocomposites, which was due to poor interfacial adhesion and agglomeration.
\end{abstract}

Keywords: Toughening; Polylactic acid; Natural rubber; Synthetic rubber; Kenaf; Biocomposite

Contact information: School of Materials and Mineral Resources Engineering, Universiti Sains Malaysia, 14300 Nibong Tebal, Penang, Malaysia; *Corresponding author: ihanafi@usm.my

\section{INTRODUCTION}

Growing awareness of the inertness and environmental impact of plastics has driven the development of biodegradable polymers. The massive plastics industry is currently dominated by petroleum-based, commodity plastics such as polyethylene, polypropylene, and polystyrene. Despite all the advantages offered by these polymers, they are not environmentally friendly. The life cycle of a synthetic polymer starts from crude oil that is refined to obtain compounds that undergo polymerization. High energy consumption and a large carbon footprint are associated with the processing and manufacturing of plastics. The depletion of fuel is also a concern. After their application, polymers are often being dumped into landfills, where they last for decades. The resistance toward degradation results in landfill overuse and pollution.

Polylactic acid (PLA) is a biodegradable aliphatic polyester derived from renewable resources such as corn plant, sugarcane, and potato. The production of PLA begins by synthesizing lactic acid, which is the monomer of PLA, followed by polymerization. Lactic acid can be derived from the plants via bacterial fermentation of a carbohydrate or chemical synthesis (Castro-Aguirre et al. 2016). PLA offers several advantages, including biodegradability, biocompatibility, comparable strength, and other mechanical properties. Due to the high cost and limited availability of PLA, most of the earlier applications have been in the medical sector to produce implant devices, 
sutures, and scaffolds. The production of PLA then increased, allowing it to be used in the packaging and textile industries (Murariu and Dubois 2016).

However, the bottlenecks of wider PLA applications are the brittleness and slow crystallization rate. The glass transition temperature of PLA is around $60{ }^{\circ} \mathrm{C}$, which is relatively high, resulting in low toughness and brittleness in room temperature applications. The limitations of PLA can be overcome by several methods such as copolymerization, plasticizer addition, and polymer blending (Lan et al. 2013; Maiza et al. 2015; Ostafinska et al. 2015). Melt mixing or simple blending is preferable because it is the most economical and convenient approach to enhance the toughness of PLA. Theoretically, the brittle polymer can be toughened by incorporating softer and flexible materials. Lee et al. (2019) investigated the toughness and rheological characteristics of PLA and acrylic core shell rubber (CSR) blends. Prior to melt blending via extrusion, the CSR was synthesized through emulsion polymerization, where the core was from polybutyl acrylate and the shell was from poly(methyl methacrylate). Based on the tensile test, the PLA/CSR blend showed ductile fracture behavior and failed after plastic deformation with a higher elongation. Increment in toughness of PLA resulted in a decreasing tensile strength and Young's modulus. The toughening mechanism occurred from the internal cavitation and interfacial debonding.

Numerous types of rubber are available for use as a toughening agent. Phattareteera and Pattamaprom (2019) compared the viscosity effect of masticated natural rubber (NR) and synthetic isoprene rubber (IR) on the properties of PLA. Generally, rubber has a relatively high molecular weight and a long molecular chain. This nature of rubber prevents good compatibility within the blends. Therefore, mastication is required to reduce the molecular weight. While comparing the toughening effect of masticated NR and IR, it was found that masticated NR contributed to higher mechanical properties. After the mastication process, the viscosity of both rubbers was reduced. However, toughening was more prominent in the blend with NR, due to the presence of non-rubber components such as lipids and proteins. The optimum mastication time was $12 \mathrm{~min}$, as a longer time resulted in decrement of impact and elongation at break.

Klinkajorn and Tanrattanakul (2019) attempted to improve the compatibility of PLA and epoxidized natural rubber (ENR) blend by using maleic anhydride (MA). The earlier stage of the work began by grafting MA onto ENR, to produce ENR-g-MA as the compatibilizing agent. The blending process was carried out in an internal mixer, followed by compression molding to produce the specimen. The binary blend without the compatibilizer showed decrement in the mechanical properties, and it was observed that the rubber dispersed in relatively bigger particle size. The enhancement of miscibility with the addition of the compatibilizer was shown by the smaller rubber droplets, a decrease in the glass transition temperature of PLA, and an increase in the mechanical properties.

The use of eco-friendly materials has impacted the fabrication of composites. Biocomposites, which include natural fibers, are a good alternative for tailoring the overall properties of a polymer. Several types of natural fibers have been incorporated into PLA matrix to improve the mechanical properties or to enhance the crystallization of PLA, including abaca, flax, and hemp. Among these natural fibers, kenaf has a good potential due to its rapid growth and comparable physical and mechanical properties (Ashori et al. 2006; Kaiser et al. 2011). Han et al. (2012) investigated the reinforcing mechanisms in kenaf fiber/PLA and kenaf fiber/polypropylene (PP) composites. The flexural strength and modulus of PLA/ kenaf were higher than PP composites. However, no remarkable difference in dispersion and distribution was observed via the morphological study. Kenaf fibers act as nucleating agents, which promotes the nucleation of the matrix phase in the composite. A review on kenaf fiber composites by 
Tholibon et al. (2019) showed that kenaf currently has been incorporated into the biodegradable polymer matrix driven by environmental concerns. Otherwise, kenaf fibers have been reported to have successfully reinforced commodity polymers such as $\mathrm{PP}$, polyester, and epoxy.

The concept of rubber toughening on PLA is a promising approach. However, there are several factors that need to be considered, such as the suitable type of rubber. The objective of the present study was to investigate the toughening effect of three different types of rubber on the PLA biocomposite. The three types of rubber studied include natural rubber, styrene butadiene rubber, and acrylonitrile rubber. Otherwise, the effect of kenaf fiber loading was also studied. To date, there has been no study reported on rubber toughened PLA/kenaf biocomposites. Processability and the water absorption of the biocomposite were reported. The mechanical properties were assessed from the tensile properties and impact strength.

\section{EXPERIMENTAL}

\section{Materials}

Polylactic acid (PLA) with an extrusion grade of 4032D produced by Nature Works Co. Ltd., USA was purchased from A.R. Alatan Sdn. Bhd (Kedah, Malaysia). The specific gravity of the PLA pellet was $1.24 \mathrm{~g}$ per $\mathrm{cm}^{3}$. Three types of rubber were used, which were natural rubber (NR), styrene butadiene rubber (SBR), and nitrile butadiene rubber (NBR). All rubbers were supplied by Zarm Scientific and Supplies Sdn. Bhd. (Bukit Mertajam, Pulau Pinang). The NR used was SMR L and was produced by the Kerilla Factory. It had a Mooney viscosity of 82 and an ash content of 0.38 wt.\%. The SBR used was 1502 grade. Meanwhile, NBR DN 3350 was used, which had a Mooney viscosity of 45 to 55 and an ash content of $0.8 \mathrm{wt} . \%$. The bound acrylonitrile content was 32 to $34 \%$. The kenaf core powder was supplied by Lembaga Kenaf \& Tembakau Negara (Kelantan, Malaysia). It was sieved and dried before use. The average particle size was $30.67 \mu \mathrm{m}$.

\section{Methodology}

Biocomposite preparation

PLA/rubber/kenaf biocomposites were prepared via melt mixing using an internal mixer (Thermo Haake Rheomix, Model R600/610) (Selangor, Malaysia) at 180 ${ }^{\circ} \mathrm{C}$ for $10 \mathrm{~min}$ with rotor speed of $50 \mathrm{rpm}$. PLA and rubber composition were fixed at $90 / 10$ wt.\%, while the kenaf loading was varied from 0 to 20 parts per hundred (phr), as shown in Table 1. Prior to melt mixing, the PLA and kenaf were dried $24 \mathrm{~h}$ at $70{ }^{\circ} \mathrm{C}$ (Cole Parmer Oven, Model: EW 52412-86) (Selangor, Malaysia), and the rubber was masticated. Dumbbell-shaped samples (Type IV ASTM D638) and impact samples (ASTM D256) were prepared by compression molding (GoTech Testing Machine, Model KT-7014) (Taichung, Taiwan). The samples were kept in a desiccator until further testing.

\section{Processing torque and stabilization torque}

The torque measurement was taken at $15 \mathrm{~s}$ intervals during the mixing period in internal mixer. The final torque at the tenth minute was recorded as the stabilization torque.

\section{Water absorption}

The water absorption test was carried out according to ASTM D570 (2018) with 5 samples per formulation. Prior to testing, the samples were dried for $24 \mathrm{~h}$ at $50{ }^{\circ} \mathrm{C}$ and 
then the initial weight was recorded using an electronic balance (Sartorius, Model: BS224S) (Kuala Lumpur, Malaysia). The samples were immersed in distilled water at room temperature for 30 days. The water absorption percentage was calculated according to Eq. 1,

$$
W_{a}(\%)=\left[\left(W_{f}-W_{i}\right) \div W_{i}\right] \times 100
$$

where $W_{a}$ is the water absorption percentage, $W_{f}$ is the final weight, and $W_{i}$ is the initial dry weight.

Table 1. Composition of Biocomposite

\begin{tabular}{|c|c|c|c|c|c|c|}
\hline Biocomposite & Composition & PLA (wt.\%) & NR (wt.\%) & NBR (wt.\%) & $\begin{array}{c}\text { SBR } \\
\text { (wt.\%) }\end{array}$ & KF (phr) \\
\hline PLA/NR/KF & $90 / 10$ & 90 & 10 & - & - & - \\
\cline { 2 - 7 } & $90 / 10 / 5$ & 90 & 10 & - & - & 5 \\
\cline { 2 - 7 } & $90 / 10 / 10$ & 90 & 10 & - & - & 10 \\
\cline { 2 - 7 } & $90 / 10 / 15$ & 90 & 10 & - & - & 15 \\
\cline { 2 - 7 } & $90 / 10 / 20$ & 90 & 10 & - & - & 20 \\
\hline \multirow{5}{*}{ PLA/NBR/KF } & $90 / 10$ & 90 & - & 10 & - & - \\
\cline { 2 - 7 } & $90 / 10 / 5$ & 90 & - & 10 & - & 5 \\
\cline { 2 - 7 } & $90 / 10 / 10$ & 90 & - & 10 & - & 10 \\
\cline { 2 - 7 } & $90 / 10 / 15$ & 90 & - & 10 & - & 15 \\
\cline { 2 - 7 } & $90 / 10 / 20$ & 90 & - & 10 & - & 20 \\
\hline PLA/SBR/KF & $90 / 10$ & 90 & - & - & 10 & - \\
\cline { 2 - 7 } & $90 / 10 / 5$ & 90 & - & - & 10 & 5 \\
\cline { 2 - 7 } & $90 / 10 / 10$ & 90 & - & - & 10 & 10 \\
\cline { 2 - 7 } & $90 / 10 / 15$ & 90 & - & - & 10 & 15 \\
\cline { 2 - 7 } & $90 / 10 / 20$ & 90 & - & - & 10 & 20 \\
\hline
\end{tabular}

\section{Tensile properties}

The tensile test was conducted according to ASTM D638 (2018) using an Instron 3366 universal testing machine (Norwood, MA). The crosshead speed was fixed at $10 \mathrm{~mm}$ per min with a gauge length of $50 \mathrm{~mm}$ at room temperature. The load cell was set at $10 \mathrm{kN}$. Five samples were tested for each composition and the average value of tensile strength, tensile modulus, and elongation at break were calculated.

\section{Impact properties}

The un-notched Izod impact test of biocomposites was performed according to the ASTM D256 (2018) standard and on the Zwick Impact tester Model 5101 (Ulm, Germany). The dimension of the samples was 12.7 by 64 by $3.2 \mathrm{~mm}^{3}$. The pendulum of $7.5 \mathrm{~J}$ energy was used and five samples were tested for each composition.

\section{Morphological study}

Both the tensile and the impact fractured surface were studied via field emission scanning electron microscope (FESEM Supra 35VP; Zeiss, Oberkochen, Germany). The samples were mounted on an aluminium stub, followed by a sputter coating with a thin layer of gold to prevent charging and poor resolution. A Polaran SC 515 sputter coater (Polaran Equipment Ltd., East Sussex, UK) was used.

\section{RESULTS AND DISCUSSION}

\section{Processing Torque and Stabilization Torque}

Processability is an important parameter for polymeric materials, which measures the ability of the material to flow and form into the desired shape. One of the 
approaches to examine the processability of a composite is by measuring the toque during the mixing process. Torque measured via the internal mixer is associated with material resistance to shear action. Figure 1 illustrates the processing torque of the PLA/NR/KF biocomposite during the melt blending period. The curve and trend of the processing torque are similar for all compositions with other types of rubber. Initially, when PLA was added into the mixing chamber, the torque increased sharply. Additionally, as the PLA started to melt, the torque decreased. At $2 \mathrm{~min}$, the increment of torque was due to the loading of rubber and kenaf. The addition of kenaf restricted the mobility of the PLA molecule chain, resulting in a viscosity increment and rising torque. The torque gradually decreased and reached a stabilized torque at the end of the mixing period.

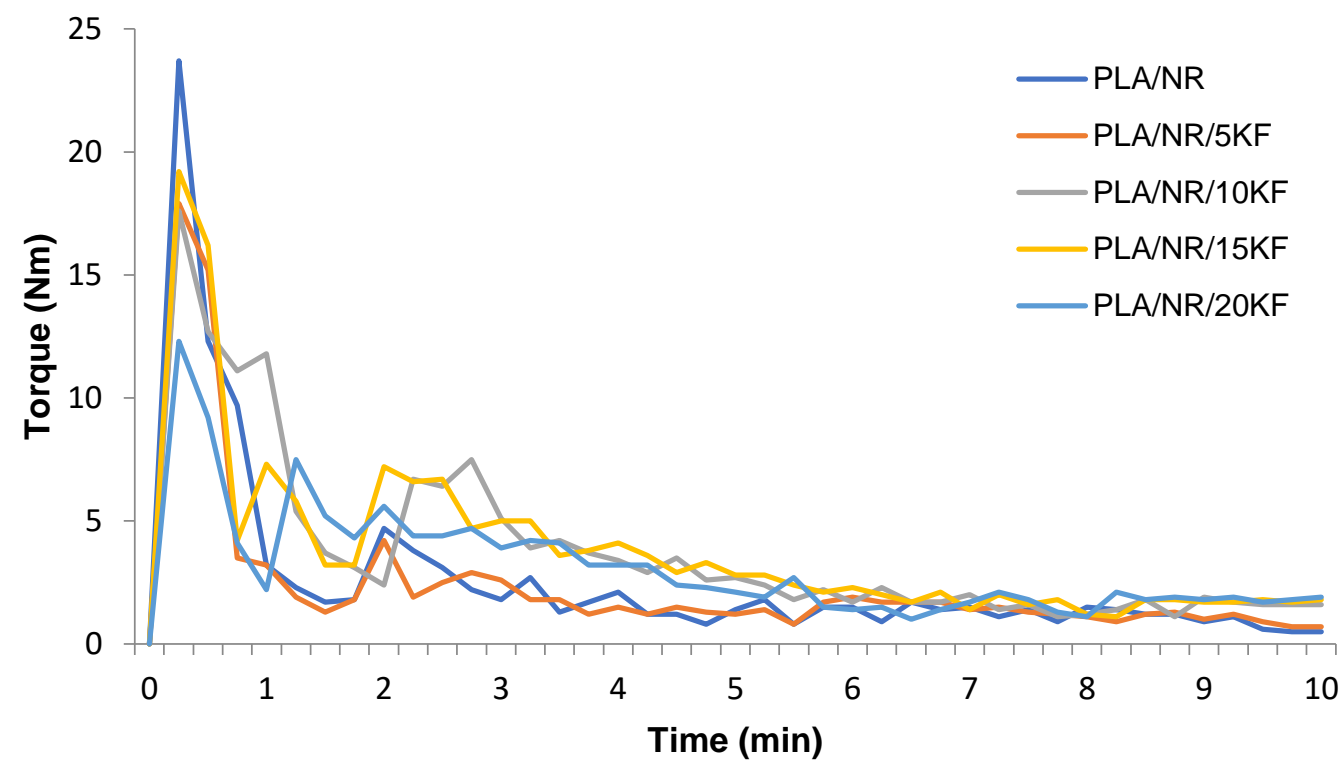

Fig. 1. Processing torque of the PLA/NR/KF biocomposite

Figure 2 shows the stabilization torque of the biocomposite with different types of rubber and kenaf loading. The final torque at the end of the mixing process is also known as the stabilization torque. In polymer processing, the stabilization torque is the relative measure of the viscosity in the polymer melt (Demir et al. 2006). In melt blending, the materials melt before compaction and fusion of the polymer to produce a homogenous polymer melt. The stabilization torque increased with the increasing kenaf loading, and a similar observation was observed for each type of rubber used. At $20 \mathrm{phr}$ kenaf loading, the stabilization torque was highest. This is due to the presence of more rigid particles in the polymer melt, which resulted in a higher resistance to rotation of the rotor. This indicates that the viscosity of the polymer melt increased with the addition of kenaf.

Generally, all types of rubber used exhibited shear thinning behavior, in which the viscosity decreased with an increasing shear rate as polymer molecules align during melt blending. When comparing the different types of rubber, the biocomposite with NR showed the highest stabilization torque. This is because NR has a higher viscosity. Therefore, it exerts more resistance to the rotation of the rotor. Synthetic rubber such as NBR and SBR are synthesized and manufactured to have a lower molecular weight than NR. When the molecular weight is lower, the chain is shorter, resulting in a lower viscosity and ease of processing. According to the material datasheet of each type of rubber used, the Mooney viscosity of NR, SBR, and NBR were 82, 46 to 58, and 45 to 55 respectively. The PLA/SBR.KF biocomposite showed a higher stabilization torque 
than PLA/NBR.KF due to the bulky styrene group in the polymer chain. This eventually restricted the chain movement during melt blending.

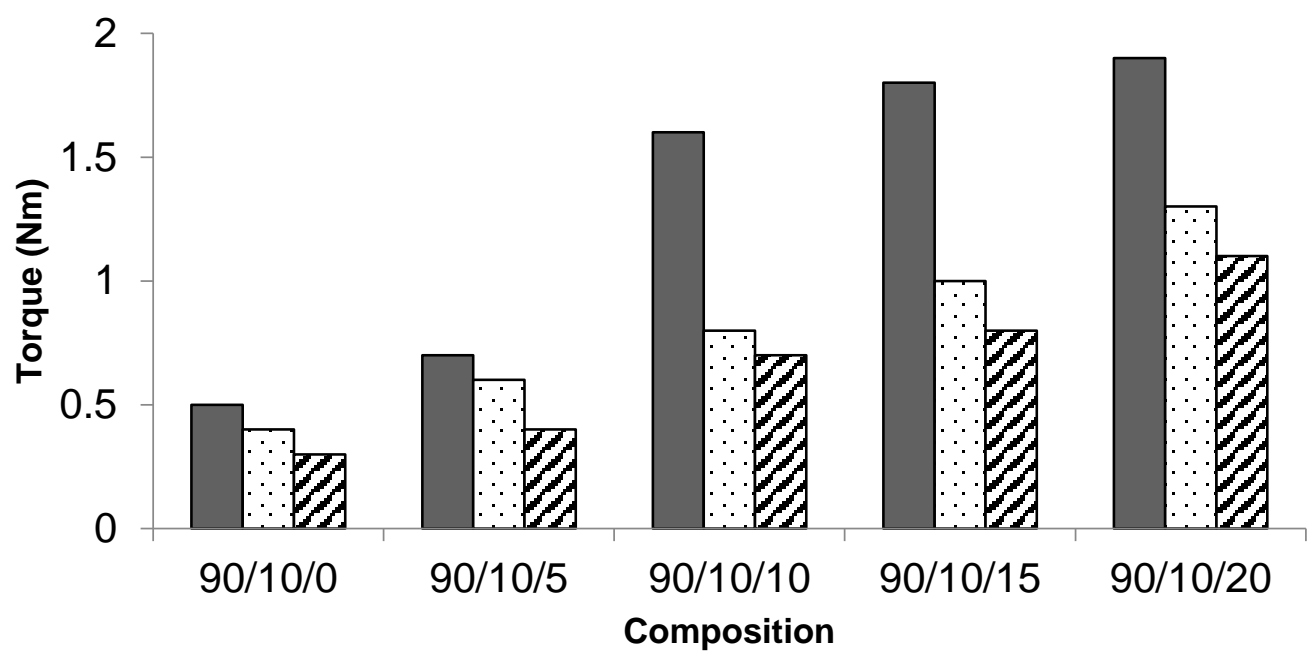

口PLA/NR/KF biocomposite $\square \mathrm{PLA} / \mathrm{SBR} / \mathrm{KF}$ biocomposite $\square \mathrm{PLA} / \mathrm{NBR} / \mathrm{KF}$ biocomposite

Fig. 2. Stabilization torque of the biocomposite

\section{Water Absorption}

Physical properties such as water absorption and moisture resistance are very important for natural fiber reinforced composites, because they act as a measure of shape/dimension stability during service life. Otherwise, the biodegradability of the composite is greatly influenced by the water absorption capability. Water absorption is affected by the chemical composition, fiber content, and the filler-matrix interaction. The effect of kenaf loading and types of rubber on the water absorption is shown in Fig. 3. The water absorption percentage of the biocomposite increased with an increasing kenaf loading. This is due to the hydrophilic nature of kenaf. Higher kenaf loading resulted in more free hydroxyl group, which has the tendency to bind with water molecules via hydrogen bonding (Ragunathan et al. 2011). Thus, this enhanced the water absorption of the biocomposite.

Natural fiber is made up of mostly cellulose and hemicellulose, which reacts with water molecules. As a result of water absorption, the fiber swells and leads to microcracks that become the largest water transport medium through the fiber-matrix interface (Munoz and Garcia-Manrique 2015; Mochane et al. 2019). The agglomeration of kenaf started to occur at a higher loading. This forms voids around the kenaf allowing more water to penetrate the biocomposite. Another important factor for water absorption is the interfacial adhesion. The difference in polarity between the PLA and kenaf contributed to the poor interfacial adhesion, resulting in higher water absorption percentage.

Migration of water inside the polymer composites occurs by diffusion. Three different factors affect the diffusion mechanism, including concentration gradient, molecular structure, and molecular interaction. The different types of rubber resulted in a different water absorption percentage in the biocomposites. The PLA/NBR/KF biocomposite showed the highest water absorption followed by the PLA/SBR/KF and $\mathrm{PLA} / \mathrm{NR} / \mathrm{KF}$ biocomposites. NBR is a polar rubber. Therefore, a stronger interaction with the hydroxyl group and nitrile group is predicted, which enhances the water uptake. While both SBR and NR are non-polar rubbers, they resulted in lower water absorption capability (Arayapranee and Rempel 2013). 


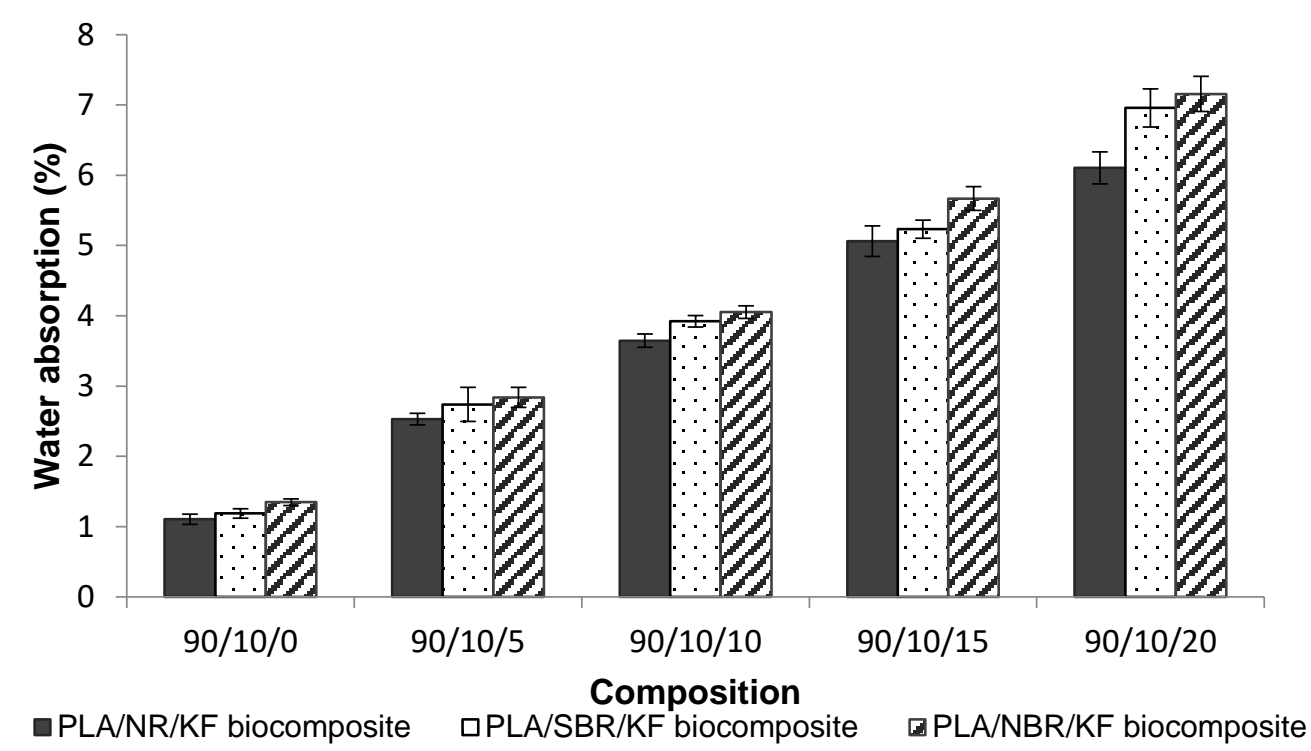

Fig. 3. Water absorption percentage of the biocomposite

\section{Tensile Properties}

The tensile properties of the polymer blend and composites are greatly correlated with the morphology, volume fraction, interfacial adhesion, and compatibility. Table 2 shows the tensile properties of the biocomposite with different types of rubber and various kenaf loadings. The tensile strength decreased with the increasing kenaf loading. The decrement of tensile strength to the volume fraction factor may be explained by the reduction of the PLA phase. In the biocomposite, three components are present, and the PLA phase contributed to the overall strength as it exhibited the highest strength. Besides that, the tensile strength of the composite is greatly affected by the interfacial adhesion and compatibility. The introduction of kenaf had basically deteriorated strength due to the incompatibility of the filler and matrices. In the main matrix, PLA is hydrophobic. Therefore, it is theoretically not compatible with highly hydrophobic kenaf. The incompatibility eventually resulted in a weak interfacial adhesion in the biocomposite. When the force was applied during the tensile test, the stress transfer from the filler to the matrix was poor. Therefore, a lower tensile strength was obtained. This observation is consistent with the data reported by Petinakis et al. (2009) and Fu et al. (2005).

However, while comparing the types of rubbers incorporated into the biocomposite, the PLA/NR/KF biocomposite showed the highest tensile strength, followed by the PLA/SBR/KF and PLA/NBR/KF biocomposites. Natural rubber (NR) has a unique characteristic over synthetic rubber, because NR can undergo a straininduced crystallization phenomenon. Upon application of the force/strain, the initially amorphous material becomes a better crystalline structure by arranging the chains (Candau et al. 2014; Waesateh et al. 2018). Synthetic rubbers usually have lower strength compared to NR, due to the presence of more natural components such as proteins and fatty and inorganic materials. The tensile strength of NR is higher than synthetic rubber, which has irregular chain structures and is amorphous, as it does not crystallize upon stretching. For example, in SBR the presence of a phenyl group prevents the re-arrangement and crystallization when stretched (Poh et al. 2001). NBR was predicted to contribute to a higher tensile strength of the biocomposite due to its polarity and possible interactions. The PLA/NBR/KF biocomposite showed the lowest tensile strength. The only plausible explanation is due to the lower green strength of NBR compared to the superior NR properties. 
Table 2. Tensile Properties of Biocomposites

\begin{tabular}{ccccc}
\hline Biocomposite & Composition & $\begin{array}{c}\text { Tensile strength } \\
(\mathbf{M P a})\end{array}$ & $\begin{array}{c}\text { Elongation at } \\
\text { break }(\%)\end{array}$ & $\begin{array}{c}\text { Tensile modulus } \\
(\mathbf{M P a})\end{array}$ \\
\hline PLA/NR/KF & $90 / 10 / 0$ & 41.39 & 10.44 & 1459.60 \\
\cline { 2 - 5 } & $90 / 10 / 5$ & 38.88 & 5.50 & 2020.50 \\
\cline { 2 - 5 } & $90 / 10 / 10$ & 38.24 & 3.25 & 2281.25 \\
\cline { 2 - 5 } & $90 / 10 / 15$ & 37.85 & 2.13 & 2411.25 \\
\hline PLA/SBR/KF & $90 / 10 / 20$ & 34.21 & 1.57 & 2578.40 \\
\cline { 2 - 5 } & $90 / 10 / 0$ & 38.26 & 8.40 & 2209.67 \\
\cline { 2 - 5 } & $90 / 10 / 5$ & 36.00 & 2.16 & 2393.67 \\
& $90 / 10 / 10$ & 35.07 & 1.77 & 2634.67 \\
\cline { 2 - 5 } PLA/NBR/KF & $90 / 10 / 15$ & 30.54 & 1.34 & 2728.67 \\
\cline { 2 - 5 } & $90 / 10 / 20$ & 26.86 & 1.03 & 2898.33 \\
\cline { 2 - 5 } & $90 / 10 / 0$ & 37.95 & 7.53 & 2208.67 \\
\cline { 2 - 5 } & $90 / 10 / 5$ & 36.03 & 2.12 & 2475.33 \\
\cline { 2 - 5 } & $90 / 10 / 10$ & 34.77 & 1.64 & 2596.67 \\
\cline { 2 - 5 } & $90 / 10 / 15$ & 28.35 & 1.12 & 2666.67 \\
\hline
\end{tabular}

The incorporation of kenaf decreased the elongation at break as the loading increased. This is due to the nature of kenaf, which is rigid and stiff. The presence of kenaf throughout the PLA/rubber matrices restrained the biocomposite from deformation/elongation because the segmental chain movement was restricted. A similar observation was reported by researchers in the works of natural fiber reinforced by a polymer composite (Ertas et al. 2019; Murariu and Dubois 2016). According to Tiwari et al. (2015) in a work on rice husk ash/polyvinyl chloride composite, the addition of a rigid filler eventually restricted movement and displacement of polymer chains, which resulted in a higher stiffness. Comparing the effect of different rubbers, $\mathrm{PLA} / \mathrm{NR} / \mathrm{KF}$ exhibited the highest elongation at break, followed by the PLA/SBR/KF and PLA/NBR/KF biocomposite. This observation showed that NR has a larger toughening effect on the biocomposite. Higher elongation at break means the specimen can undergo more deformation before failure. When tensile force is exerted on the specimen, the rubber phase acts as a toughening agent by absorbing more energy. Deformation starts in the rubber phase via cavitation.

As NR has the propensity of strain induced crystallization, the rubber chains in the biocomposite align themselves to form a more organized structure and higher crystallization (Trabelsi et al. 2002). The force applied is the source of energy for rearrangement. For synthetic rubbers such as SBR and NBR, the force is solely absorbed for cavitation. Another explanation for lower elongation at break for SBR is the restriction of chain movement. This is due to the presence of bulky phenyl groups, which restricted the chain movement when stress is applied.

The tensile modulus is measured as the force required to deform any material, which also is a direct reflection of the stiffness. With respect to kenaf loading, the tensile modulus increased with the increasing kenaf loading. Modulus increment in composites are attributed to several factors such as formation of hydrogen bonding, high crystallinity index of filler, and a stiffening effect (Cheng et al. 2009). A high intrinsic modulus of kenaf resulted in a stiffening effect in the biocomposites. The chain mobility and deformation ability of PLA and rubber matrices were restricted by dispersed kenaf particles (Ahmad and Baharum 2018; Xian et al. 2018). However, the 
incorporation of kenaf into biocomposites is beneficial to overcome the loss of modulus due to blending with the soft rubber phase. Besides that, at high loading, kenaf particles tend to agglomerate, resulting in the increment of the tensile modulus.

Theoretically, most elastomeric materials have a low modulus of elasticity, which allows them to sustain more deformation. Different types of rubber used in the biocomposite contributed to various moduli. The structure of rubber determined the ability to withstand deformation and the interaction in the system. The PLA/SBR/KF biocomposite showed the highest tensile modulus compared to the PLA/NR/KF and PLA/NBR/KF biocomposites. SBR is made up from two polymeric components that produce a copolymer of the styrene and butadiene group. The presence of the bulky styrene group on the SBR chain reduces the chain mobility. Therefore, a higher modulus was observed. While for NBR, the nitrile group in the structure formed very strong bonding within the polymeric chains. The stronger bonds caused the NBR chain to become stiffer, thus having a higher modulus.

Figure 4 shows the morphologies of the tensile fractured surface of the biocomposites with different kenaf loadings and types of rubber at 500x magnification. The addition of rubber enhanced the toughness of PLA, which is demonstrated by the ductile fracture observed when compared to the brittle fracture commonly associated with neat PLA. The SEM micrographs showed that the biocomposites exhibited phase separation morphology, in which rubber particles dispersed in a spherical shape with poor interfacial adhesion within the PLA matrix. The binary PLA/NR blend showed a much finer structure with smaller rubber particles. Besides that, binary PLA/NR blend without kenaf was observed to have more plastic deformation on the tensile fractured surface and a higher amount of plastically deformed material. More plastic deformation of the matrix means more energy will be absorbed during the tensile test. This is supporting evidence for the highest elongation at break and tensile strength.

The fibrillation of the polymer matrix during the imposed tensile force showed that the polymer had higher tensile strength, higher flexibility, and failed in a ductile manner. For the PLA/NR binary blend, the fibrillation was obvious with small ore fibrils throughout the entire fractured surface. Meanwhile in the PLA/NBR binary blend, less fibrillation occurred. Even though the PLA/SBR binary blend fibrils were bigger, the amount of fibrillation was less. Another important morphological feature in the tensile fractured surface was the size and number of holes. A review on rubber enhanced polymeric materials by Caldona and co-workers (2016) pointed out that the size of rubber particles affects the toughening efficiency. Smaller rubber particles contributed to a higher energy dissipation and more roughening effect. Based on the fractures surface of the binary blend without kenaf, the rubber particles size increased. NR was the smallest, followed by NBR and SBR.

A biocomposite with $10 \mathrm{phr}$ kenaf loading showed less fibrillation and tearing effect. Kenaf fiber was well distributed throughout the matrix and some fiber pullout occurred. Fiber pull out occurs in a composite due to weak interfacial adhesion between the fiber and the matrix phase. Theoretically, the interfacial adhesion of the biocomposite is predicted to be poor because of the hydrophilic nature of the kenaf and hydrophobic PLA matrix. The interaction and morphology of the biocomposite were not affected much by the incorporation of more polar rubbers such as NBR. This might be due to the low content of rubber in the biocomposite. PLA/NR/KF at $10 \mathrm{phr}$ kenaf loading exhibited less fibrillation when compared to PLA/NBR/KF and PLA/SBR/KF. Besides that, for PLA/NR/KF biocomposites, some kenaf fiber was still intact in the matrix. Most of the kenaf fiber in the fracture surface have noticeable gaps with matrices, indicating that interaction is relatively poor. 
bioresources.com

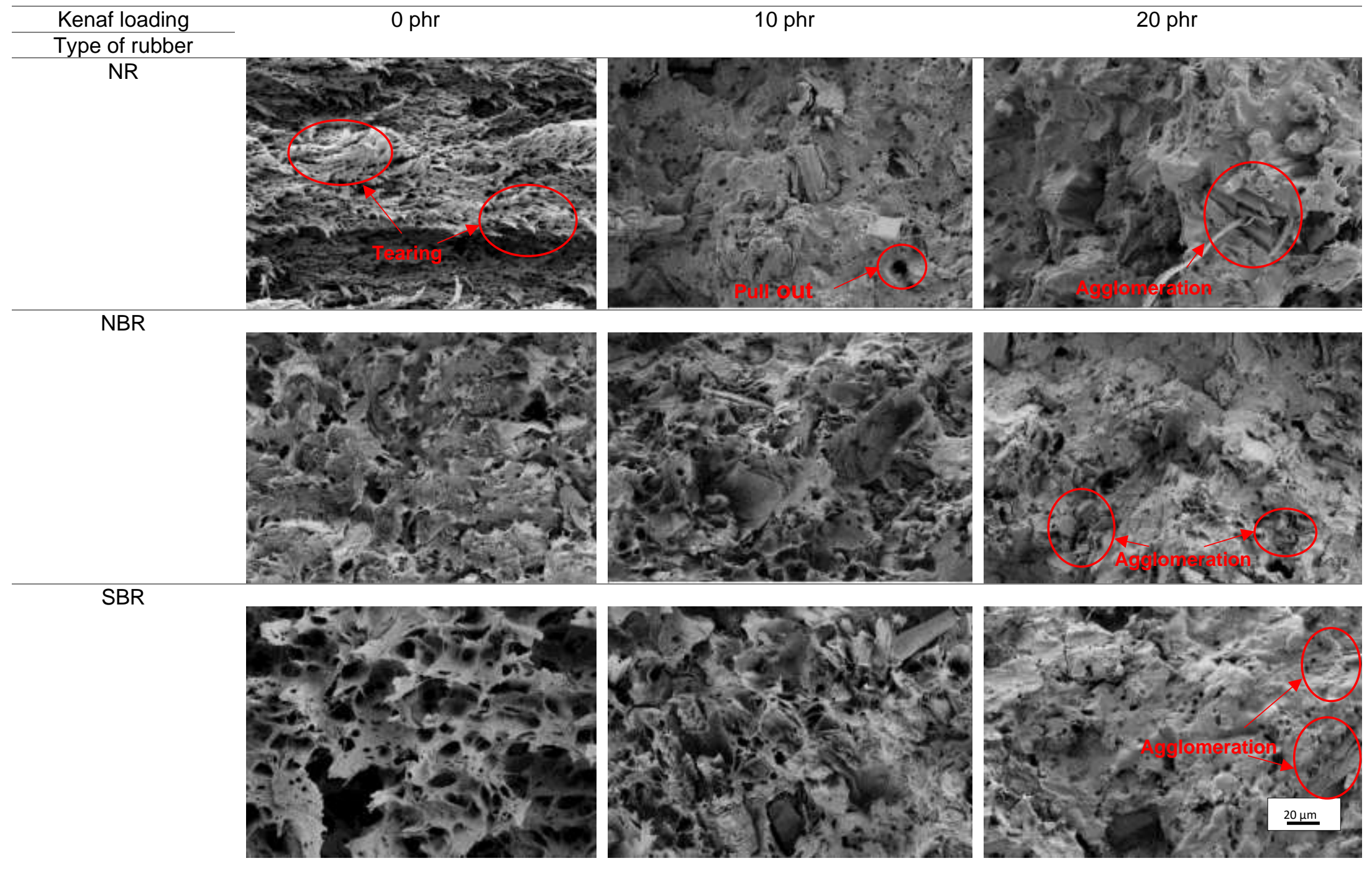

Fig. 4. SEM images of the tensile surface of the biocomposites

Alias et al. (2020). "PLA/rubber/kenaf composites," BioResources 15(3), 5679-5695. 5688 
The only possible polar interaction between kenaf and PLA is weak hydrogen bonding between hydroxyl groups and carbonyl in the ester group of PLAs. Incorporation of fiber is to support loads transmitted by the matrix, but if the interfacial adhesion is not good, the fiber is not able to function to enhance mechanical properties.

At $20 \mathrm{phr}$ kenaf loading, more fiber pull out was observed, indicating weaker interfacial adhesion between the kenaf and PLA/rubber matrix. The same observation was recorded for all biocomposites with all types of rubber. The micro voids on the fractures surface resulted from fiber pull out. Since the surface of the voids were smooth, no resistance or strong attachment by the matrix during the tensile force was exerted on the specimen. Another drawback of natural fiber is the tendency to form agglomeration, especially at high fiber loadings. Abundant hydroxyl groups on the surface of natural fiber induced interaction among themselves, resulting in agglomerates. Once the agglomeration occurred, the stress transfer was interrupted, causing premature failure, which lowered the mechanical properties. For a biocomposite at $20 \mathrm{phr}$ kenaf loading, several agglomerates were observed. Therefore, the tensile strength and elongation at break decreased. The SEM observation was consistent with the trend of tensile properties.

\section{Impact Properties}

Impact strength is a measure of the ability of a material to withstand/resist sudden impact force. Figure 5 shows the variation of impact strength in the PLA/rubber/KF biocomposites at different kenaf loadings and types of rubber. Increasing kenaf loading decreased the impact strength of the biocomposite. Besides that, PLA and kenaf are profoundly incompatible due to the difference of polarity. More local stress concentrations are generated in biocomposites at high kenaf loadings, eventually initiating or favoring crack growth. Poor interfacial adhesion within the phases also led to decrement of impact strength. Generally, in composites the fillers or fibers withstand more stress than the matrix, in which the stress transfer from these two phases needs to be efficient to enhance the mechanical properties (Tokoro et al. 2008). When the interfacial adhesion is poor, the stress is not transferred efficiently, resulting in premature failure that sacrifices the properties.

Besides that, incorporation of rigid fillers or fibers into the polymeric matrix tends to reduce the flexibility and ability to deform. The presence of kenaf reduces the local motion of polymer chains during the application of impact force. Moreover, polarity of kenaf induces the tendency of fiber to fiber interaction due to the high hydroxyl group bound (Mohamed et al. 2018). This occurrence results in fiber agglomeration especially at high kenaf loadings. Without agglomeration, the fiber already initiates crack propagation between the fiber to the matrix interface. When agglomeration occurs, the interfacial adhesion or interaction is less likely to exist. Therefore, crack initiation and propagation are easily developed (Thomason and Rudeiros-Fernandez 2018). Thus, the impact strength of biocomposites were the lowest at 20 phr kenaf loading.

Biocomposites with natural rubber exhibited the highest impact strength compared to SBR and NBR. In the rubber toughened polymer, the rubber particles need to be dispersed throughout the brittle polymer phase to increase the toughness and ductility. The mechanisms involved are primarily higher energy absorption by the rubber phase through shear yielding, crazing, cavitation, and shear banding (Alias and Ismail 2019). Two important criteria for rubber toughening are the size of the rubber particle dispersed and the interfacial adhesion. Referring to the SEM images of biocomposite without any kenaf loading (Figs 4,6) the droplets or dots throughout the PLA phase are the rubber phase. The distribution of rubber was observed as homogenous and well-distributed. However, the droplet size was bigger for SBR, followed by NBR, and NR. This may be the key explanation to the better toughening effect by NR. 


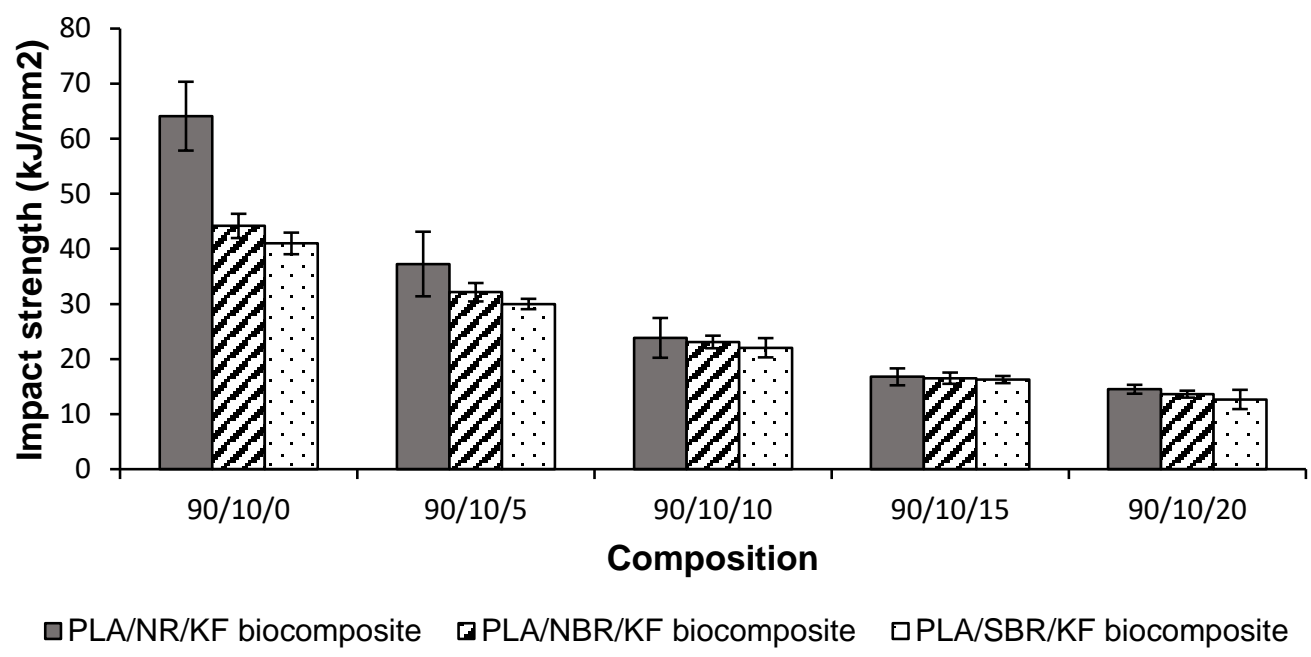

Fig. 5. Impact strength of the PLA/rubber/KF biocomposites

Structure-property correlations can be investigated via morphological study of the fracture surface, cross section, and the surface of the composite itself. Figure 6 shows the SEM images of impact fracture surfaces of the biocomposite with various types of rubber and kenaf loadings at 200x magnification. Without kenaf, the PLA/rubber binary blend showed a smoother impact-fractured surface with step structure resulting from the crack propagation. A material will have higher impact strength if it is able to absorb and dissipate more energy. According to Zhou and Burkhart (2010), step structure is one of the characteristic tails in the micro-shear banding mechanism. Energy is dissipated via shear banding. Therefore, the biocomposite has a higher impact strength.

When comparing the different types of rubber in the binary blend without kenaf, the step structure was more obvious in the PLA/NR, followed by the PLA/NBR and PLA/SBR. The back, tiny holes throughout the surface are attributed to the rubber particles being dispersed, in which the SBR particles were biggest when compared to the NBR and NR particles. Two major points can be related to this observation. SBR has a rigid styrene group, which reduced the chain mobility regarding the dispersion while mixing. During mixing, the rubber phase needs to be broken down into smaller particles and dispersed uniformly. Since the SBR is more rigid due to the presence of the bulky styrene group, a slower dispersion process will occur during melt blending. In the rubber toughened polymer, the particle size plays an important role for an effective toughening mechanism. Rubber particles within the PLA matrix are supposed to be the stress concentrators, which undergo deformation and induce cavitation. The energy involved in all mechanisms resulted in a higher total energy for the crack propagation. Large rubber particles could promote crack propagation causing decreased energy absorption and impact strength.

With the addition of kenaf, the fractured surfaces became more irregular and rougher. Generally, a rougher morphology is associated with a higher impact strength due to more work of fracture that occurs while resisting the impact load. However, the roughness exhibited from the fractured surface of the biocomposite resulted from the presence of the kenaf fiber. Particle debonding and cracking were observed after the addition of kenaf and became more prominent at higher kenaf loadings. The higher kenaf loading resulted in agglomeration of particles due to the fiber to fiber interaction. Smooth holes left the on surface indicates that the interfacial adhesion is insufficient. Otherwise, fiber breakage also occurred during the impact test. 


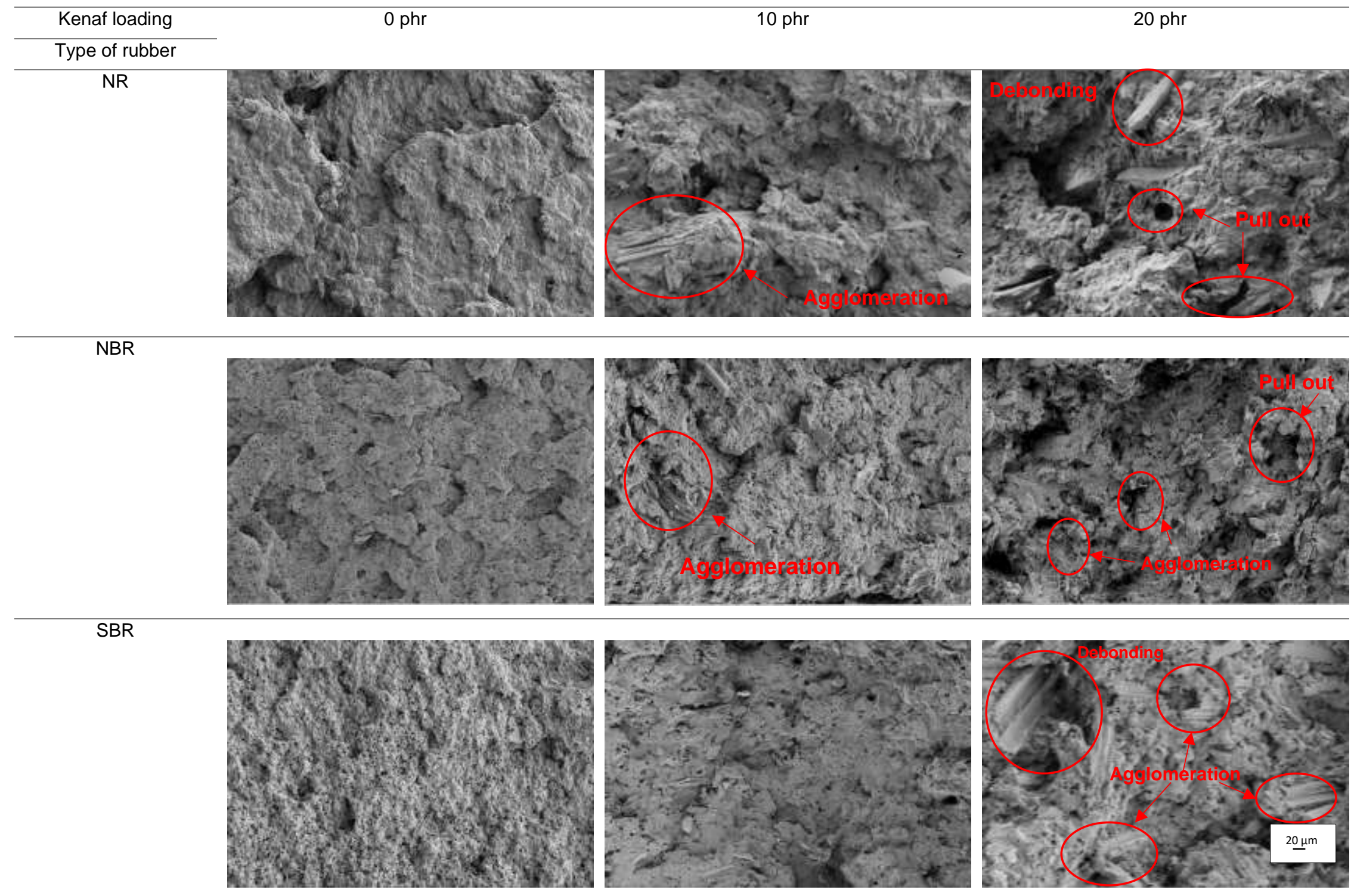

Fig. 6. SEM images of the impact fractured surface of the biocomposite 
Agglomeration within the biocomposite eventually was the stress concentration point and was susceptible to premature failure when an external force was imposed on the specimens. The crack propagation becomes easier around the agglomerates as the fiber to matrix interaction is relatively weak. Several researchers reported similar observations and effects of the fiber agglomeration to the properties of the composite (Ragunathan et al. 2018; Daramola et al. 2019). At 20 phr kenaf loading, more kenaf fibers were pulled out from the fractured surfaces. This indicated weak bonding of the kenaf-matrix interface, which eventually caused debonding and cavitation. The presence of cavities is where cracks tend to grow and spread when the particles are removed. These morphological findings supported the trend of impact strength with the increased kenaf loading and types of rubber.

\section{CONCLUSIONS}

1. Poly(lactic acid) (PLA)/rubber/kenaf biocomposites were successfully prepared using natural rubber (NR), styrene-butadiene resin (SBR), and nitrile butadiene rubber (NBR) to tailor the properties of the biocomposites.

2. The incorporation of kenaf fiber increased the water absorption, which can be attributed to the hydrophilicity of natural fiber. When comparing the type of rubber, NBR showed the highest water absorption percentage as NBR is a polar rubber. Non-polar rubbers such as NR and SBR have less tendency to interact with water molecules during immersion.

3. Increasing kenaf loading resulted in a decrement of tensile strength, elongation at break, and impact strength in the biocomposites. This is due to the incompatibility of PLA-kenaf, PLA-rubber, and rubber-kenaf. The morphological analysis of fractured surfaces via SEM showed poor interfacial adhesion and agglomeration especially at higher kenaf loadings.

4. Tensile strength, elongation at break, and the impact strength of PLA/NR/KF were the highest, followed by PLA/NBR/KF and PLA/SBR/KF. The mechanical properties of biocomposites varied according to the type of rubber.

5. PLA/NR/KF biocomposites showed the highest properties when compared to SBR and NBR. This was attributed to the superior, high green strength of NR and the ability to undergo the strain induced crystallization phenomenon. However, the tensile modulus increased with the increasing kenaf loading due to the intrinsic rigidity of kenaf. The presence of the bulky styrene group in SBR also contributed to the highest tensile modulus among NR and NBR.

6. Overall, the results obtained have laid out an important aspect to achieve better properties, which is the necessity of interfacial adhesion improvement among the components within biocomposite.

\section{ACKNOWLEDGEMENT}

The authors acknowledge support from the School of Materials and Mineral Resources Engineering, Universiti Sains Malaysia and financial support from the USM Fellowship Scheme and RUI-grant (1001/PBahan/8014150). 


\section{REFERENCES CITED}

Ahmad, A. A., and Baharum, A. (2018). "Biocomposite of epoxidized natural rubber/poly (lactic acid)/catappa leaves as shoe insole," Journal of Polymer Science and Technology 3(2), 20-28.

Alias, N. F., and Ismail, H. (2019). "An overview of toughening polylactic acid by an elastomer," Polymer-Plastics Technology and Materials 1-24. DOI: 10.1080/25740881.2018.1563118

Arayapranee, W., and Rempel, G. L. (2013). "Effects of polarity on the filler-rubber interaction and properties of silica filled grafted natural rubber composites," Journal of Polymers 279529, 1-9. DOI: 10.1155/2013/279529

Ashori, A., Harun, J., Raverty, W. D., and Yusoff, M. N. D. (2006). "Chemical and morphological characteristics of Malaysia cultivated kenaf (Hibiscus cannabinus L.) fibre," Polymer Plastics Technology and Engineering 45(1), 131-134. DOI: 10.1080/03602550500373782

ASTM D256 (2018). "Standard test methods for determining the Izod pendulum impact resistance of plastics," American Society for Testing and Material, West Conshohocken, Pennsylvania.

ASTM D570 (2018). "Standard test method for water absorption of plastics," American Society for Testing and Material, West Conshohocken, Pennsylvania.

ASTM D638 (2018). "Standard test method for tensile properties of plastics," American Society for Testing and Material, West Conshohocken, Pennsylvania.

Caldona, E. B., De Leon, A. C, Pajarito, B. B., and Advincula, R. C. (2017). “A review on rubber-enhanced polymeric materials," Polymers Reviews 57(2), 311-338. DOI: 10.1080/15583724.2016.1247102

Candau, N., Laghmach, R., Chazeau, L., Chenal, J., Gautheir, C., Biben, T., and Munch, E. (2014). "Stain-induced crystallization of natural rubber and crosslink densities heterogeneities," Macromolecules 47, 5815-5824. DOI: 10.1021/ma5006843

Castro-Aguirre, E., Iniguez-Franco, F., Samsudin, H., Fang, X., and Auras, R. (2016). "Poly (lactic acid)-mass production, processing, industrial application and end of life," Advanced Drug Delivery Reviews 107, 333-366. DOI: 10.1016/j.addr.2016.03.010

Cheng, Q., Wang, S., and Rials, T. (2009). "Poly (vinyl alcohol) nanocomposites reinforced with cellulose fibrils isolated by high intensity ultrasonication," Composites Part A: Applied Science and Manufacturing 40(2), 218-224. DOI:

10.1016/j.compositesa.2008.11.009

Daramola, O. O., Akinwekomi, A. D., Adediran, A. A., Akindote-White, O., and Sadiku, E. R. (2019). "Mechanical performance and water uptake behaviour of treated bamboo fibre-reinforced high-density polyethylene composites," Heliyon 5(7), e02028. DOI: 10.1016/j.heliyon.2019.e02028

Demir, H., Atikler, U., Balkose, D., and Tihminlioglu, F. (2006). "The effect of fiber surface treatments on the tensile and water absorption properties of polypropylene-luffa fiber composites," Composites Part A 37, 447-456. DOI: 10.1016/j.compositesa.2005.05.036

Ertas, M., Altuntas, E., and Cavdar, A. D. (2019). "Effects of halloysite nanotubes on the performance of natural fiber filled poly (lactic acid) composites," Polymer Composites 110. DOI: $10.1002 / \mathrm{pc} .25284$

Fu, S. Y., Lauke, B., Zhang, Y. H., and Mai, Y. W. (2005). "On the post-mortem fracture surface morphology of short fiber reinforced thermoplastics," Composites: Part A 36, 987-994. DOI: 10.1016/j.compositesa.2004.11.005

Han, S. O., Karevan, M., Na Sim, I., Bhuiyan, M. A., Jang, Y. H., Ghaffar, J., and Kalaitzidou, K. (2012). "Understanding the reinforcing mechanisms in kenaf fiber/PLA and kenaf fiber/PP composites: A comparative study," International Journal of Polymer 
Science 679251, 1-8. DOI: 10.1155/2012/679252

Kaiser, M., Anuar, H., and Razak, S. (2011). "Ductile-brittle transition temperature of polylactic acid-based biocomposite," Journal of Thermoplastic Composite Materials, 26(2), 216-226. DOI: 10.1177/0892705711420595

Klinkajorn, J., and Tanrattanakul, V. (2019). "Compatibilization of poly (lactic acid)/epoxidized natural rubber blend with maleic anhydride," Journal of Applied Polymer Science 137 (3), 48297, 1-9. DOI: 10.1002/app.48297

Lan, X., Li, X., Liu, Z., He, Z., Yang, W., and Yang, M. (2013). “Composition, morphology and properties of poly (lactic acid) and poly (butylene succinate) copolymer system via coupling reaction," Journal of Macromolecular Science Part A 50(8), 861-870. DOI: 10.1080/10601325.2013.802196

Lee, J. Y., Kwon, S. H., Chin, I., and Choi, H. J. (2019). "Toughness and rheological characteristics of poly (lactic acid)/acrylic core-shell rubber blends," Polymer Bulletin 76, 5483-5497. DOI: 10.1007/s00289-018-2662-x

Maiza, M., Benaniba, M., Quintard, G., and Massardier-Nageotte, V. (2015). "Biobased additive plasticizing polylactic acid (PLA)," Polímeros 25(6), 581-590. DOI: 10.1590/0104-1428.1986

Mochane, M. J., Mokhena, T. C., Mokhothu, T. H., Mtibe, A., Sadiku, E. R., Ray, S. S., Ibrahim, I. D., and Daramola, O. O. (2019). "Recent progress on natural fiber hybrid composites for advanced applications: A review," eXPRESS Polymer Letters 13(2), 159198. DOI: 10.3144/expresspolymlett.2019.15

Mohamed, W. Z. W., Baharum, A., Ahmad, I., Abdullah, I., and Zakaria, N. E (2018). "Mengkuang fiber reinforced thermoplastic natural rubber composites: Influence of rubber content on mechanical properties and morphology," Malaysian Journal of Analytical Sciences 22 (5), 906-913. DOI: 10.17576/mjas-2018-2205-19

Munoz, E., and Garcia-Manrique, J. A. (2015). "Water absorption behavior and its effect on the mechanical properties of flax fibre reinforced bioepoxy composites," International Journal of Polymer Science 390275, 1-10. DOI: 10.1155/2015/390275

Murariu, M., and Dubois, P. (2016). "PLA composites: From production to properties," Advanced Drug Delivery Reviews 107, 17-46. DOI: 10.1016/j.addr.2016.04.003

Ostafinska, A., Fortelny, I., Nevoralova, M., Hodan, J., Kredatusova, J., and Slouf, M. (2015). "Synergistic effects in mechanical properties of PLA/PCL blends with optimized composition, processing, and morphology," RSC Advances 5(120), 98971-98982. DOI: 10.1039/C5RA21178F

Petinakis, E., Yu, L., Edward, G., Dean, K., Liu, H., and Scully, A. D. (2009). "Effect of matrix-particle interfacial adhesion on the mechanical properties of poly (lactic acid)/wood-flour micro-composites," Journal of Polymers and The Environment 17, 8394. DOI: 10.1007/s10924-009-0124-0

Phattarateera, S. and Pattamaprom, C. (2019). "Comparative performance of functional rubbers on toughness and thermal property improvement of polylactic acid," Materials Today Communications 19, 374-382. DOI: 10.1016/j.mtcomm.2019.02.012

Poh, B. T., Ismail, H., Quah, E. H., and Chin, P. L. (2001). "Cure and mechanical properties of filled SMR L/ENR 25 and SMR L/SBR blends," Journal of Applied Polymer Science 81(1), 47-52. DOI: 10.1002/app.1411

Ragunathan, S., Nurul, S. O., Abdillahi, K. M., and Ismail, H. (2018). "Effect of maleic anhydride grafted polypropylene on polypropylene/recycled acrylonitrile butadiene rubber/ empty fruit funch composite," Journal of Vinyl \& Additive Technology, 275-280. DOI: $10.1002 / \mathrm{vnl} .21571$

Ragunathan, S., Ismail, H., and Kamarudin, H. (2011). "Mechanical properties, water absorption, and swelling behaviour of rice husk powder filled polypropylene/recycled acrylonitrile butadiene rubber ( $\mathrm{pp} / \mathrm{nbrr} / \mathrm{rhp}$ ) biocomposites using silane as a coupling 
agent," BioResources 6(4), 3714-3726. DOI: 10.15376/biores.6.4.3714-3726

Tholibon, D., Tharazi, I., Sulong, A. B., Muhamad, N., Ismail, N. F., Md Radzi, M. K. F., Radzuan, N. A. M., and Huie, D. (2019). "Kenaf fiber composites: A review on synthetic and biodegradable polymer matrix," Journal Kejuruteraan 31(1), 65-76. DOI: 10.17576/jkukm-2019-31(1)-08

Thomason, J. L., and Rudeiros-Fernández, J. L. (2018). "A review of the impact performance of natural fiber thermoplastic composites," Frontiers in Materials 5, 1-18. DOI: 10.3389/fmats.2018.00060

Tiwari, P., Choudhary, S., and Choudhary, M. (2015). "Study on mechanical, thermal and morphological properties of RHA filled PVC composite," International Journal of Scientific Engineering and Applied Science 1(5), 265-281.

Tokoro, R., Vu, D. M., Okubo, K., Tanaka, T., Fujii, T., and Fujiura, T. (2008). "How to improve mechanical properties of polylactic acid with bamboo fibers," Journal of Material Science 43(2), 775-787. DOI: 10.1007/s10853-007-1994-y

Trabelsi, S., Albouy, P. A., and Rault, J. (2002). "Stress-induced crystallization around a crack tip in natural rubber," Macromolecules 35, 10054-10061. DOI: 10.1021/ma021106c

Waesateh, K., Saiwari, S., Ismail, H., Othman, N., Soontaranon, S., and Hayeemasae, N. (2018). "Features of crystallization behavior of natural rubber/halloysite nanotubes composites using synchrotron wide-angle X-ray scattering," International Journal of Polymer Analysis and Characterization 23, 260-270. DOI: 10.1080/1023666X.2018.1438773

Xian, Y., Ma, D., Wang, C., Wang, G., Smith, L., and Cheng, H. (2018). "Characterization and research on mechanical properties of bamboo plastic composites," Polymers 10, 814, 1-15. DOI: 10.3390/polym10080814

Zhou, R. J., and Burkhart, T. (2010). "Mechanical properties and morphology of microparticle and nanoparticle-filled polypropylene composites," Journal of Material Science 45, 3013-3022. DOI: 10.1007/s10853-010-4304-

Article submitted: March 22, 2020; Peer review completed: April 18, 2020; Revised version received: May 29, 2020; Accepted: May 30, 2020; Published: June 2, 2020.

DOI: 10.15376/biores.15.3.5679-5695 